\title{
PRONOMINALISATION IN SOUTH ASIAN LANGUAGES: OF PEOPLE AND THEIR ACTIONS*
}

Tanmoy Bhattacharya

By looking at agreement in Indo-Aryan (IA), and Munda languages, it is suggested that the apparent similarity of a certain phenomenon across unrelated languages is not a sufficient condition for contact induced change. In particular, I will investigate the phenomenon of "multiple agreement" in detail in Munda languages to show that it is not the same as agreement in contiguous IA languages.

Keywords: pronominalisation, Munda, clitic, agreement, agree

\section{Multiple agreement in CMP languages}

There exists a possible contact situation between the "Central Māgadhan Prākrit" (CMP) languages (see Bhattacharya 2016 for an explanation of the coinage there initiated for various reasons) like Maithili, Magahi, Angika, and some North Munda (Kherwarian) languages, like Santali, Mundari, Ho, etc., as these languages are spoken in the same extended geographical area. This is perhaps the reason why Chatterji(1926) obviously pointed towards these latter group of languages when faced with the phenomenon of multiple agreement (or "intricacies of the verbal system," see the quotations below) in CMP languages, although a careful reading of earlier scholars like Grierson (1903), would have revealed the verb agreement pattern for him.

It is clear from the following quotation that the multiple agreement phenomenon of the CMP languages was obvious to Grierson:

"The principal difficulty to the beginner in the study of Maithili, is the bewildering maze of the verbal forms." ... "This is due to the fact that the verb agrees not only with the subject, but with its object." (Grierson 1903: 25)

However, for Chatterji (1926), these languages held the following features:

i. "The verb-system of Maithili and Magahi seems to be a rather late development, originating or asserting itself long after the differentiation of the Māgadhī speeches." ii. "... the intricacies of the later Maithili were absent in Old Maithili."

iii. Talking about the language of Vidyāpati $\left(14^{\text {th }}\right.$ C), Chatterji states that "... especially noticeable is the simplicity of verb-system, with its freedom from the ramifications of pronominal infixes and affixes."

iv. Chatterji conjectures further that the pronominal affixation could be due to influx of Kōl people from South, first as "Chikā-Chikī" dialect and later spreading further. (all italics are mine)

Chatterji thus talks about a possible contact situation "from south" of the CMP language area with Munda languages synchronically coexisting; he doesn't necessarily talk about the path of Munda migration into the area.

However, there exists certain differences between the two agreement systems, that apart from highlighting the well discussed difference between agreement and cliticization, emphasizes a clear difference between the two types. Thus, these evidences point towards a direction of independent development of each type in the respective languages.

2 Empirical facts of clitics in Munda and agreement in CMP languages

The various differences between the empirical facts of the two phenomena in these two groups of languages are discussed below (from Bhattacharya, 2016).

(a) Clitics are forms of pronominals

Table (1) shows that in Mundari the clitics and the pronominals are quite similar. In the CMP languages, on the other hand, as in (1a) in Maithili, the pronominals for 'he (hon.)' and 'you (non-hon.)' are $o$ and tora, whereas the agreement marker carrying the 3 Hon+2Non-hon fused morpheme is thunh.

[Keynote speech delivered at the $38^{\text {th }}$ Annual Conference of Linguistic Society of Nepal] 
Table 1: Mundari agreement markers

\begin{tabular}{|c|c|c|c|}
\hline & SG & DL & PL \\
\hline $1^{\text {st }}$ Inclusive & $-\tilde{n} /-a \tilde{n}$ & -lay/-alay & -bu/ -abu \\
\hline $1^{\text {st }}$ Exclusive & --- & -lin/ -alin & -le/ -ale \\
\hline 2nd & $-\mathrm{m} / \mathrm{-am}$ & -ben/ -aben & -pe/ -ape \\
\hline $3 \mathrm{rd}$ & $\begin{array}{l}\text {-el-il-e?/-1P/ } \\
\text { ae? }\end{array}$ & --kin/ -akin & -ko/ -ako \\
\hline
\end{tabular}

(1) o tora dekh-əl-thunh

He.H you.NH.ACC/DAT see-

$\operatorname{PAST}(3 \mathrm{H}+2 \mathrm{NH})$

'He (H) saw you(NH).'

[Yadav (1996)]

(b) Optionality of agreement marking

Although optionality of object marking is noticed in Sora (a South Munda language), in the CMP languages, such agreement cannot be optional:

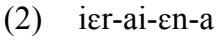

go/come-CLOC-N.SFX-GEN

tiki aninji guden-le

after they call-PST

'After he came, he called them.'

[Anderson and Harrison, 2008:330]

(c) Bi-personal verb forms are not the norm

Either the subject (in (3a) with an intransitive verb) or both the subject and the object (as in (3b) with a causativized form of the same intransitive verb) is marked; also the subject agreement clitic ( $k o$ and $e ?$ in bold) is found on the Locative in (3a) and the causative subject in (3b), respectively, whereas the object clitic is incorporated into the verb in (3b) here:
a. hon-ko ote-re=ko dub-ke-n-a child-PL ground-LOC=3PL:SUBJ sit- COMPL-INTR-IND
'Children sat on the ground.'

b. Sona hon-ko=e? dub-ke-d-ko-a

Sona child-PL=3SG:SUBJ sitCOMPL-TR-3PL:OBJ-IND

'Sona made the children sit.' [Mundari, Osada 2008:121]

Although Sora is a south Munda language not ever in contact with languages in Bihar, it also has a rare instance of "bi-personal" verb form, that is, whenever there is another argument in the sentence with a different person feature, the verb is marked for both (as in (4)). However, marking both the arguments in the verb is not the norm.

(4)

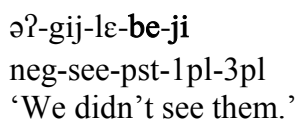

[Sora, Anderson and Harrison, 2008:328-330]

Note thus that in (3b), the verbal form is marked with only argument clitic (object and subject, respectively), bi-personal verbal form of agreement, as in (4) are not the norm. Again, this feature of single argument agreement is a departure from the multiple agreement we notice in CMP languages.

(d) Pro-clitic split

The Munda languages have pro-clitics which often split across the verb and a pre-verbal word; for example, the subject clitic in the following is on the object and the object clitic is on the verb, shown here in bold (as in (3b)):

a. pusi-kin seta-ko=kin hua-ke-d-ko-a cat-DL dog-PL=3DL:SUBJ bite COMPL-TR-3PL:OBJ-IND

'The two cats bit the dogs.'

b. seta -kin pusi-kin=kohua-ke-d-kin-a dog-PL cat-DL=3PL:SUBJ biteCOMPL-TR-3D:OBJ-IND

'The dogs bit the two cats.'

[Mundari, Osada 2008:108]

The verb here carries a single clitic agreement morpheme (representing the object); this is different from CMP languages (see (c) above).Observe also the fact that the phenomenon of pro-clitic split is specific only to Munda languages with accompanying cliticization.

(e) Presence of applicative suffixes

Applicatives are employed to mark indirect objects: in Santali and Mundari, the indirect object is marked with an applicative morpheme, $a$ in the first case and $-m a$ in the latter with the verb:

a. dal-a-n-a-e 
62 / Pronominalization ...

strike-APPL-1SG:OBJ-FIN-3SG:SUBJ

'He strikes/ will strike for me.'

[Santali: Ghosh 2008: 55]

b. am seta-ko=n om-a-ma-ta-n-a

2S Gdog-PL=1SG:SUBJ give-BEN-

APPL-2SG-PROG-INTR-IND

'I am giving the dogs to you.'

[Mundari, Osada 2008:122]

Use of applicatives is not found in CMP languages.

Summarising the observation so far, let us focus on the difference that is relevant for our purpose here in this paper, namely, the order of affixes in Santali (and Munda in general):

\section{V-Asp/Aux-Agr $\mathbf{A}_{\mathbf{0}}-\mathrm{Mood}_{\text {/C/Fin-Agr }}$}

Whereas, in CMP languages, as shown in Bhattacharya (2016), the order of affixes is:

$$
\mathrm{V}-\operatorname{Agr}_{\mathrm{s}}-\operatorname{Agr}_{\mathrm{o}}
$$

Along with the clear difference between the status of agreement morphemes of the two languages; the morphemes denote clitics in Santali, and in CMP languages, they denote agreement affixes.

3 The origin of pronominalisation

For Max Müller (The languages of the Seat of the War in the East: with a survey of three families of language, Semitic, Arian, and Turanian. 1855. London: Williams \&Norgate, p86) "(T)he third family is the Turanian. It comprises all languages spoken in Asia or Europe not included under the Arian and the Semitic families, with exception perhaps of the Chinese and its dialects." Although Hodgson had earlier in 1849 included Chinese too in this group, which hints at his later coinage of a separate family called "Tibeto-Burman": "Tamulians, Tibetans, Indo-Chinese, Chinese, Tangus, Mongols, and Turks are so many branches of another single family, viz., the Turanian" (1849 p:3). The $19^{\text {th }}$ century European construct "Turanian" thus became the wastebasket category where widely unrelated languages were dumped; partly due to their overzealousness in "mapping" the world, and partly dictated by war reasons. This latter point is highlighted in Max Müller when he reasons that Tungusic languages, which extend from north China to
Siberia up to the river Tunguska, are to be discounted since "they are not likely to appear on the theatre of war;" similarly, the Mongolic languages.

Though Hodgson (1849) 'unites' the Himalayas, Indo-China and Tibet as speaking languages of the same family (TB) that is marked by "syntactic poverty", among other traits, Hodgson (1856) lists a series of facts, one of them being verb pronominalisation, which, according to him, offers evidence of genetic relation between the Turanian languages; this also gave rise to the "Austric" thesis (Bhattacharya 2017). The pronominal system of the Turanian languages according to Hodgson are "greatly developed" and consist of the following traits:

a. Separate forms for personal (independent) and possessive forms of pronouns;

b. Separate inclusive and exclusive forms for $1 \mathrm{st}$ person pronouns;

c. Different sets of possessive pronouns: one used disjunctively (i.e. as a free form) and the other conjunctively (i.e. as an affix);

d. Distinction between dual and plural number categories;

e. Verb pronominalisation;

f. Prefixation of noun possessive forms and suffixation of verb pronominal affixes;

g. A prevailing verb structure consisting of root + transitive/intransitive marker + pronominal suffix;

h. The morphological conflation of 2 nd and $3^{\text {rd }}$ persons in TB and Dravidian in opposition to 1 st person forms.

As we shall see many of these observations, noted more than 150 years ago, are accurate. He further considers that the Himalayish and Munda languages show pronominalisation in fullest form while other Turanian languages either lack it entirely or show much more impoverished forms. To his credit though, Hodgson does not even hint at a directional view of the spread of this feature from, what many people considered, substratal Munda to TB. However, the substratum thesis was a very popular one in the $19^{\text {th }}$ century language studies in and around India, and Konow, being in-charge of parts of the LSI ((3) 1 ) and 
1(1)), drew a directional link between Himalayan TB languages and Munda by proposing that substratum Munda influence is the cause of pronominalisation in the former:

"It therefore seems probable that Mundas or tribes speaking a language connected with those now in use among the Mundas, have once lived in the Himalayas and have left their stamp on the dialects there spoken at the present day" (LSI 3(1)s179 and 1(1): 56).

Of course, there have been other theses, for example, Henderson:

"It appears not unlikely that improved knowledge of the Chin languages and of others equally remote geographically from the so-called pronominalized groups will bring further similarities to light. In this event linguists may be obliged to conclude that, contrary to what has often been supposed, pronominalisation is after all a genuine Tibeto-Burman family trait" (1957:327).

However, as Bauman (1975), convincingly argues, pronominalisation as a feature is widely distributed across North, Northwest, Northeast and Indo-China, which gives credit a native origin within TB of pronominalisation theory. As Maspero (1946) had shown, Munda and TB verb are syntactically dissimilar. For one, the pronominal affixes with the verb in TB languages seem like agreement markers and not clitics as in Munda. This has, as Bauman argues, something to do with lack of morphological case markings in Munda and their presence in TB. The disambiguation of the NOM/ ACC marked NPs in Munda is done in the verbal markings, whereas in TB, ambiguities can be recovered through case marking. There are three areas of differences between the pronominals in the two groups of languages that Bauman points out: (i) $\mathrm{TB}$ has more alternate pronominal forms than Munda; (ii) fixed position of affixes in TB as opposed to say in Santali where the subject clitic can be either on the preverbal element or appear verb-finally (Bodding, 1929:49). [So the word-finality cannot be of recent origin as conjectures in Hock (2013)]. Also, in Santali, and Munda in general, the clitic forms are easily derivable from the pronominal forms, but this not the case in case of $\mathrm{TB}$ pronominal affixes. (iii) the Munda clitics are simpler than the TB ones, it's their order relative to the root that defines them as an object. In short, the pronominalisation system of TB languages is much more complex than the Munda languages, and in fact, Pinow (1966) concludes that:

"In proto-Munda...the pronouns properly were independent, isolatable free forms. The affix character of the pronouns, which were incorporated into the verb complex as subject or object respectively, is of more recent date" (1966:183).

The classification of pronominalized languages into subgroups at least established the fact that no one scheme fits them all, which in turn means that this feature is an archaic TB feature.

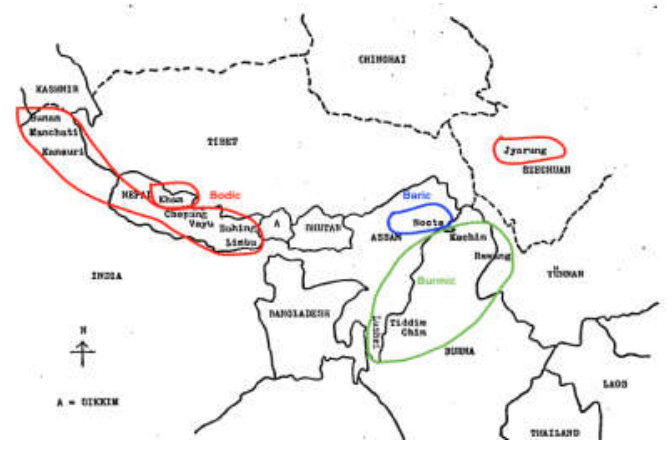

Classification of pronominalized languages modified from Bauman (1975) based on Shafer (1974)

\section{Clitics versus affixes}

There are various well-known diagnostics to test the differences between clitics and affixes. For Santali, these tests are indicated in Kidwai (2006), following Zwicky and Pullum (1983), and summarised below; it will be noted that Subject marker is more clitic-like than the Object marker:

a. Santali Subject clitic is not selective in terms of the category of the host, the latter may be nouns, postpositions, light verbs, adverbs, negation, etc. The object clitic however always appears after the Tense/ Aspect marker following the verb root, though it's not restricted as to the nature of the Tense/Aspect marker;

b. Unexpected gaps may appear with affixes (e.g. 
64 / Pronominalization ...

stride doesn't have a past participle), but not with clitics;

c. Santali clitics do not have idiosyncratic semantics, unlike affixes (-er in English);

d. Clitics cannot induce stem allomorphy;

e. Clitic placement is syntactically conditioned; the distinction between the Santali finite marker $-a$, which always appears verb-finally, and the subject clitic, which can be shown to be syntactically predicted (see below);

f. Clitics attach outside of affixes; except for the finiteness marker $-a$, the subject clitic seems to be placed mostly after all the other affixes

5 Against phonologically driven clitic-placement

With regards to $(\mathrm{v})$ above, note that there exists a vast literature on so-called $2^{\text {nd }}$ position clitics, which have been argued to be phonologically as well as syntactically conditioned. However, this literature is mostly based on research on languages in Europe. Hock (2013) is guided by such concerns, as well as trying to look for only a historical explanation of the phenomenon. Hock (2013) reasons that just because preverbal focus in SOV languages makes the rheme stronger than the theme, it also attracts the clitic. However, this assumes two things: (i) clitic-placement is a matter of prosody, and (ii) clitic-placement is centred around finding the prosodically 'strongest' element; neither of which is a proven fact.

The hypotheses listed in Hock (2013) are also driven mostly by historical concepts. For example, his contention that Munda clitics started out as clause-initial theme position only to shift later to the Wackernagel position, and it only later moved to the postverbal position via the preverbal focus position, in short, a rightward drift theory. However, later summarising the findings, Hock (2013) contends that the rightward drift to a Wackernagel position within the domain of the rheme; note that this is really a statement about the syntactic positioning of the element in question. Further on, other alternative possibilities are considered, which include, among others, placement of the clitic (as in Serbo-Croatian) after the first element following a prosodic break after the clause-initial position. For example, in Parachi (a Southeastern Iranian language), clitics attach to the leftmost element; however, it may also appear at the end of the verb, if there is no other constituent, or it may preferably attach to the constituent immediately preceding the verb; and alternatively attach to an earlier constituent for emphasis. This hints at too many possibilities and suffers from the same problem that many historical and typological accounts do - they never predict the non-availability of a position where a clitic can be placed.

Also if Hock's account were to be right, we would need to see data with other focus elements in the clause (even within the rheme) attracting the clitic (as the final alternative in Parachi indicated above), as far as I can tell, this does not happen. Given the main 'drift' in the article, it seems that all that it is certain about is the preverbal position as far as Munda is concerned; from the mere way this is proposed, it is clear that that is a syntactic position, rather than phonology guiding clitic-placement. The example in (11d) below also clearly argues against a phonologically conditioned clitic-placement theory, where the subject clitic is placed after the negation particle. In conclusion, it may be said that clitic-placement is determined both by Syntax and Phonology

6 Unmarked positions of clitics in Santali

With regards to clitic-placement in Santali, older scholarship noticed the phenomenon carefully, although various authors described them as short forms of pronominal elements (Hoffman (1903) for Mundari, Burrow (1915) for Ho, Macphail (1953) for Santali, etc.). For example, Hoffman (1903), provides the following example:

(9) nel-ko-tan-a-le

see-them-PRES-FIN-we

'We are seeing them'

Here, the pronouns in the gloss are highlighted to indicate how Hoffman viewed those elements; thus, $k o$ is the direct object and le is the subject for Hoffman in (9). However, Hoffman also remarks that: "These pronominal subjects when suffixed to Mundari Transitive or Intransitive Predicates give the latter a semblance of $a$ conjugation ..." Recall that European scholars studying these pronominalized languages in the $19^{\text {th }}$ century had very strange views about this 
issue. Thus, with regards to pronominal complexity Hodgson comments that "when viewed in connection with the paucity of true conjugational forms [recalls] the fine remark that rude people think much more of the actors than the action" (1856:135).

Macphail's (1953) view on these clitics can be understood from the following:

"If the subject of the sentence, whether noun or pronoun is animate, the short form of the pronoun is always shown on the verb. Sometime it follows the verbal ' $a$ ' at the end: more often it is attached to the previous word. If the subject is an animate pronoun, it appears first in its full form and is repeated in the short form in the verb. If a noun, the corresponding pronoun is shown in the verb. If the subject is inanimate, no pronoun is shown on the verb."

To understand the unmarked position of the subject clitic, consider the following examples from Macphail (1953):

(10) a. amdo-m bes-ge-a

youEMP-2s well-EMP-FIN

'You are well.'

b. in. do sapha-ge-ān( $(\bar{a} n=a-i n)$

IEMP clean-EMP-FIN-1s

'I am clean.'

Other examples of subject clitic placement are as follows (from Hansdah\&Murmu (2005), henceforth HM):

(11) a. insen-ok'-a-in

Igo-FUT-FIN-1s

'I shall go.'

b. in-insen-ok'-a

I-1sgo-FUT-FIN

'I shall go.'

c. inbazaar-insen-ok'-a

Imarket-1sgo-FUT-FIN

'I shall go to the market.'

d. inbazaarba-in sen-ok'-a

Imarket-1 sNEG-1 sgo-FUT-FIN

'I shall not go to the market.'
Thus, with regards to the placement of the subject clitic, we can consider the default or unmarked positions as follows:

(12) Default/ Unmarked position of the subject clitic in Santali:

a. stem-finally (postverbally), or

b. affixed to the preverbal element (ditropic)

Example (11a) shows the postverbal positioning, and $(11 \mathrm{~b}, \mathrm{c}, \mathrm{d})$ show preverbal placement of the subject clitic in in Santali. Although Hock (2013) reports as Osada (2008) (for Mundari) noting that the postverbal positioning is preferred by younger speakers, it must remembered even Bodding (1929:49) noted the postverbal position as a default position of the subject clitic in Santali. Example (11c) also clearly shows that cliticplacement is not a matter of phonology as it is not in the expected $2^{\text {nd }}$ position of the clause.

Placement of the object clitic can be ascertained from the following (besides (9) above):

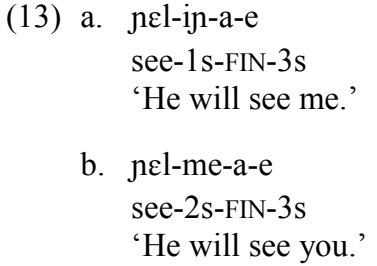

There is also the option of fully specifying the pronouns themselves in the clause as well as the following shows:

(14) a. uniinnel-in-a-e

heIsee-1s-FIN-3s

'He will see me.'

b. uniampll-me-a-e

heyousee-2s-FIN-3s

'He will see you.'

Thus, it is not true, as noted by both Kidwai (2005) and Hock (2013), that the subject clitic appears stem-finally only when all arguments of the verb are incorporated into the verb.

Cliticisation in Santali is, however, restricted to [+animate] nouns only, this is shown below for both subject and object clitics: 
66 / Pronominalization ...
(15) a. noa baha do mon'-a this flower EMP beautiful-FIN 'this flower is beautiful.'
b. nel-ked-a-e see-PST-3s-FIN-1s 'I saw it.'

Note that both direct and indirect object may not be cliticised, as in the following noted by Macphail (1953):

(16) a. gidradomæjiu-inem-ade-a childEMPwoman-1 sgive-PST.3s(DAT)-FIN '(I) gave the child to the woman.'

b. mæjiu-thengidra-inem-ked-e-a woman-tochild-1 sgive-PST-3s(ACC)-FIN '(I) gave the child to the woman.'

(16) above shows that the internal argument that is not cliticised is moved out. Note also that -adein the (a) example is shortened form of ked-ae where $-k e$ is dropped and $-a$ (as a Dative marker, as per Hoffman (1903) or Mundari) moves to the front. This dative marker is further visible in the following from HM:

(17) a. inām-in nur-me-a

Iyou-1s drop-2s-FIN

'I shall drop you.'

b. ināmmidizdhiri-nnur-ā-ām-a Iyouonestone-1 sdrop-DAT-2s-FIN

'I shall drop a stone on you.'

Note that the direct object is [-animate] in (17b) and, therefore, it does cliticise(although in English it's a PP).

Note also that the object clitics is placed after the Tense/Aspect infix, although it may not be clear form the above examples; see example below (from HM):

(18) a. nel-et-ko-kən-a-n see-PRS-3PL-be-FIN-1S

'I am seeing them.'

b. nel-et-ben-kən-tahẽnkaən-a-n see-PRS-2DL-be-PST-FIN-3SG 'I was seeing them two.'

So, the position of the object clitic in Santali is:
(19) Default/ unmarked position of the object clitic in Santali:

Between the Tense/Aspect marker and the Finiteness marker, or:

$$
\mathrm{V}-\mathrm{T} / \mathrm{ASP}-\mathrm{CL}_{\mathrm{OBJ}}-\mathrm{FIN}
$$

Like other north Munda languages like Mundari and Ho, Santali also shows the unique property of cliticising [+animate] possessive Genitives, as shown below:

(20) a. gidra menak'-ko-tin-a

child exist-3PL-1.POSS-FIN

'I have children.'

b. (uni) hopon-e idi-ket'-e-tin-a (he)son-3stake-PST.TRAN-3S-1.POSS-FIN '(He) took away my son.'

However, it is not mandatory for the genitive to cliticise on to the verb, as the following shows:
a. hopon-tin-e hec'-en-a Son-GEN-3s come-PST.INTR-FIN
'My son came.'
b. inhopon-e hec'-en-a
1s-son-3s come-PST.INTR-FIN
'My son came.'
c. in-ic hopon hec'-en-a
1S-GEN son come-PST.INTR-FIN 'My son came.'

Finally, psychological predicates in Santali seem to show a phenomenon which violates the cliticplacement typology we have seen so far; this is shown below:

(22) a. raban'-ket'-pe-a

cold-PST-2PL-FIN

'You were cold.'

b. rengec $-e d-i n-k ə n-a$

hunger-PRS-1S-BE-FIN

Lit. It hungers me ('I am hungry')

c. tetan-ko-a

thirst-3PL-FIN

Lit. It will make them thirsty ('They will be thirsty')

7 Analysis 
To come back where we started from, namely, debating the influence of Munda languages on the CMP group of languages in terms of multiple agreement, it was pointed out that there is a crucial difference between the two groups in terms of the order of agreement morphemes or clitics; this is summarised below:

(23)V-Asp/Aux-Agr $\mathbf{~}_{\mathbf{0}}$-Mood/C/Fin-Agr $\mathbf{s}_{\mathbf{s}}$

(Munda)

(24) V-T-Asp-Agr $-\mathrm{Agr}_{\mathrm{o}}$

(CMP)

Thus, the relative orders of the subject and objectindexation morphemes differ in the two groups of languages.

Agreement affixes (or clitics) are assumed to be derived through the operation of "Agree"-a dependency relation between an inflectional head and the arguments in its domain, which results into the valuation of appropriate $\Phi$-features on the head ( $\mathrm{T}$ here). Thus, when $\mathrm{T}$ agrees with the Subject DP, the latter's $\Phi$-features are copied onto T, and are then "relayed" onto the verb. This is standard Agree and is shown in (25).

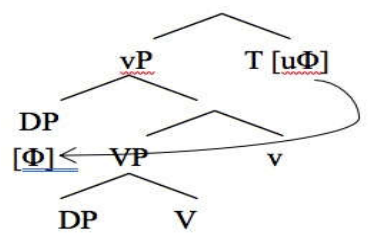

This will produce the sequence of morphemes as below:

$$
\text { V-T-AGR }
$$

However, in order to establish multi-argument agreement (as reported above for both IA and Munda), standard Agree as in (25) is not sufficient. In order to account for the fact of multi-argument agreement, the $v$ head can establish Agree with another DP-argument, namely the object DP. This possibility is sketched in (27).

Note that here the $\Phi$-features are valued on two different heads $\mathrm{T}$ and $v$, respectively, and two different cycles.

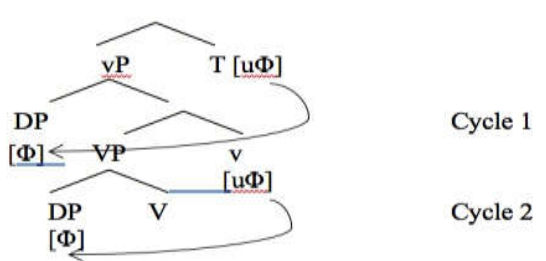

Accordingly, the "relay" of the valued features is copied further onto the $[\mathrm{V}-v]$ complex to produce the sequence as follows:

(27) V-T-AGR

However, note that this is not the order of agreement morphemes in Munda (cf. (23)). The analysis suggested for the CMP group of languages in Bhattacharya (2016) makes crucial use of the phenomenon of "Cyclic Agree" (CA) of Rezáč (2003) and Béjar (2003), which proceeds in a bottom-up fashion. Thus, in CA, the VP agreement is done first and then the derivation proceeds to do the inflectional subject agreement, by definition therefore, CA will obtain a bottomup agreement pattern; namely, that the object agreement marker will be nearer to the verb than the subject agreement marker. This is shown in (29).

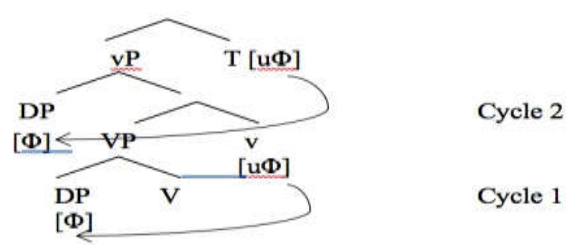

Producing a sequence such as the following, as desired for Munda languages:

$$
\text { V-AGR }{ }_{\mathrm{OBJ}}-\mathrm{T}-\mathrm{AGR}_{\mathrm{SUBJ}}
$$

There are many other details of the analysis presented as well as much of the data presented above, have all not been taken into account (though see Bhattacharya 2017), but rather the attempt has been to sketch an overall analysis based on the new notion of Cyclic Agree.

\section{Conclusions}

The argument presented in the first part of the paper suggests that it is possible to map a 
68 / Pronominalization ...

Sprachbund in the eastern foothills of the Himalayas based on the phenomenon of multipleagreement, that has emerged without necessarily inducing a contact situation. Based on various diagnostic tests, we have shown that multipleagreement may involveagreement in CMP languages, whereas cliticization in Munda languages.

Furthermore, the analysis presented has shown that the syntax of multiple agreement may involve two different types of Agree relations, namely, CyclicAgree and Standard Agree, for these two different groups of languages.

\section{References}

Anderson, Gregory and K. David Harrison. 2008. Sora. In Gregory D.S. Anderson (ed.), TheMunda Languages. London / New York: Routledge. [Routledge Language Family Series], 299-380.

Bauman, James J. 1975. Pronouns and Pronominal Morphology in Tibeto-Burman. University of California, Berkeley, Ph.D.

Bhattacharya, Tanmoy. 2018. The syntax of argumentindexation in the languages ofIndia: A case of Macro- or Microvariation? Paper presented in the Workshop on Variation in Languages, CEL, Sikkim University [March].

Bhattacharya, Tanmoy. 2017. Peopling of the Northeast:Part 3. neScholar, vol 3:1, 61-70.

Bhattacharya, Tanmoy. 2016. Inner/Outer Politeness in Central MāgadhanPrākrit Languages: Agree as Labeling. Linguistic Analysis, vol 40, 3-4, 297-336.

Chaterji, Suniti Kumar. 1926. The Origin and Development of the Bengali Language. GeorgeAllen \& Unwin, London.

Grierson, G. A. 1887. Seven Grammars of the Dialects and Subdialects of the Bihari Language: Spoken in the Province of Bihar, in the Eastern Portion of the North-Western Provinces, and in the Northern Portion of the Central Provinces. Part VII: South Maithilì-Bangālì dialect of south Bhagalpür. Printed at the Bengal Secretariat Press: Calcutta.

Grierson, G. A. 1903. Linguistic Survey of India, Vol V, Indo-Aryan Family, Eastern Group,Part II: Specimen of Bihārī and Oriya Languages. Office of the Superintendent, Government Printing, Calcutta, INDIA.

Grierson, G. A. 1909. Linguistic Survey of India, Vol III, A Manual of the Kashmiri language.
Office of the Superintendent, Government Printing, Calcutta, INDIA.

Ghosh, Arun. 2008. Santali. In Gregory D.S. Anderson (ed.), The Munda Languages. London / New York:Routledge. [Routledge Language Family Series]: 11-98.

Hansdah, R.C. and Murmu, N.C. 2005. A Framework for Learning and Understanding Santali in OlChiki Script. Wesanthals e-group Technical Report No. 1.

Henderson, Eugenie J. A. 1957. Colloquial Chin as pronominalized language. 3SOAS 20:323-27.

Hock, Hans Henrich. 2013. Backernagel is Wackernagel lite. On the "P-minus 2" clitics of Santali. Lingua Posnaniensis, vol. LV (2). The Poznan Society for theAdvancement of the Arts and Sciences.

Hodgson, Brian. 1849. [I849d] On the aborigines of north-eastern India. JASB 18:350-59. [reprinted in Miscellaneous essays relating to Indian subjects, Vol. 2, 1- 10. 1880].

Hodgson, Brian. 1856. Aborigines of the Nilgiris with remarks on their affinities. JASB 25:498-522. [reprinted in Miscellaneous essays relating to Indian subjects, Vol. 2, 125-44. 188Q].

Hoffman, Rev. J. 1950. Encyclopedia Mundarica, 13 Vols, Patna: Superintendent of Government Printing, Bihar.

Kidwai, Ayesha. 2005. Santali 'Backernagel' Clitics: Distributing Clitic Doubling." In: Bhattacharya, T.(ed.) 2005. The Yearbook of South Asian Language and Linguistics; New York, Mouton: 189-207.

Macphail, R. M. 1953. An Introduction to Santali. Calcutta: Firma KLM Private limited.

Müller, Max. 1854. Le.er to Chevalier Bunsen on the Classification of the Turanian Languages.

Müller, Max. 1855. The languages of the Seat of the War in the East: with a survey of three families of language, Semitic, Arian, and Turanian. London: Williams \&Norgate.

Osada, Toshiki. 2008. Mundari. In Gregory D.S. Anderson (ed.), The Munda Languages. London / New York: Routledge. [Routledge Language Family Series]: 99-164.

Yadav, Ramawater. 1996. A Reference Grammar of Maithili. The Hague: Mouton. 